\title{
Analyzing Interrelated Markets in the Electricity Sector - The Case of Wholesale Power Trading in Germany
}

\author{
Anke Weidlich and Daniel Veit
}

\begin{abstract}
This paper reports on results from an agent-based simulation model that comprises three interrelated markets in the electricity sector: a day-ahead electricity market, a market for balancing power, and a carbon exchange for $\mathrm{CO}_{2}$ emission allowances. Agents seek to optimize trading strategies over the two electricity markets through reinforcement learning; they also integrate market results from emissions trading into their reasoning. Simulation outcomes show that the model is able to closely reproduce observed prices at the German power markets for the analysis period of 2006. The model is thus applicable for analyzing different market designs in order to derive evidence for policy advice; one example for such an analysis is given in this contribution.
\end{abstract}

Index Terms-Agent-Based Computational Economics, dayahead market, balancing power, $\mathrm{CO}_{2}$ emissions trading, market interrelations.

\section{INTRODUCTION}

$\mathbf{E}$ LECTRICITY markets rank among the most complex of all commodity markets operated at present. The institutions that set the framework for power generation, transportation and retail supply must be designed in a way to ensure that the three main goals of energy supply can be met: environmental sustainability, economic efficiency and security of supply. Simultaneously, technical reliability requirements, as well as transmission and unit commitment constraints must be taken into account. These requirements have resulted in the development of several interrelated markets, such as power exchanges, balancing power markets, markets for emission allowances and others. The ensemble of these interrelated markets has to be analyzed together if advice for good market design is to be derived. The analysis of markets in the electricity sector is further complicated by the presence of few dominating and vertically integrated firms. Models that assume perfect competition are inappropriate for representing this oligopoly of bidders in a realistic manner. While many theoretical approaches assume that market participants will bid competitively, and only interact once, wholesale electricity markets involve an oligopoly of bidders who trade repeatedly. This constellation encourages strategic bidding. Players seek to ameliorate their bidding strategies continually, based on their experience gained in previous trading days. Thus, realistic electricity market modeling must account for strategic bidding

A. Weidlich and D. Veit are with the University of Mannheim, Business School, Schloss, Mannheim, Germany; e-mail: \{weidlich,veit\}@unimannheim.de.

Manuscript received November 30, 2007; revised 07.02.2008. by dominant players, learning from daily repeated interaction, and for the dynamics stemming from multiple interrelated markets. In this context, the question arises which market rules or which regulatory framework is best appropriate to ensure efficient market outcomes.

The complexity of the electricity sector and its high importance for a competitive economy calls for modeling methods that are capable of representing the relevant complex aspects and allow gaining insights into the dynamics of power markets. Computational methods, and agent-based (AB) simulations in particular, are flexible and useful tools that support analysis in the process of engineering electricity markets. They also offer the possibility of modeling agents that adapt to their environment, i.e. that learn their best strategies from repeated interaction, thereby following a proposition formulated by Alvin E. Roth [1]: "models of learning with the ability to predict behavior in new environments will be a valuable addition to the designer's toolbox [...]." Agent-based modeling offers great flexibility for specifying different scenarios and can be used as fully controllable virtual laboratories for testing economic design alternatives in order to determine the particular market designs that perform best in an environment of selfish agents [2].

In this contribution, an agent-based model of several interrelated markets in the electricity sector is presented. During the last decade, many agent-based simulation models of electricity markets have been developed (see [3] for a survey). Most approaches use reinforcement learning algorithms for representing the adaptive behavior of players in the market, e.g. [4], [5], [6]; the use of genetic algorithms [7] or learning classifier systems [8] is less frequent in agent-based electricity market modeling. While earlier models only regard single, very simplified market, some recent models comprise several markets [4], and explicitly model interrelations between them [9]. The model presented here also takes into account emission trading, and, unlike many related models, is validated against empirical historical data.

The remainder of this paper is structured as follows: Section II describes the markets and agents constituting the simulation model. Section III reports the empirical validation procedure, in which a scenario representing the demand and supply situation in the reference year 2006 is simulated and compared to real-world prices of the same period. Section IV reports one example of simulation scenarios that can be run in order to analyze different market structures. Finally, Section V concludes. 


\section{The Simulation Model}

The simulation model comprises three markets: a day-ahead electricity market, a market for positive minute reserve (balancing power), and an exchange for $\mathrm{CO}_{2}$ emission allowances Agents can be categorized as market operators, generators, load serving entities, or $\mathrm{CO}_{2}$ market participants.

\section{A. Agents}

Generator agents operate power plants and sell their generation output either on the day-ahead electricity market or - if their power plants meet the technical requirements for delivering minute reserve - on the balancing power market, and buy or sell $\mathrm{CO}_{2}$ emission allowances if they operate fossil fuel fired plants. They are characterized by their power plant portfolios, where each plant is defined through several parameters such as its (constant) marginal generation cost, the net installed capacity, no-load costs, or its emission factor, denoting how much $\mathrm{CO}_{2}$ emissions are associated with every MWh of output. The merit order of the total installed capacity by all agents is depicted in Figure 5 .

Load serving entities demand electricity on the day-ahead market. They are characterized by their hourly load profiles. The load profiles applied in the simulations presented here are graphically displayed in Figure 6.

$\mathrm{CO}_{2}$ market participants other than the generator agents constitute the external demand and supply of allowances. They are characterized by their demand or supply quantity and a valuation at which they wish to sell or buy $\mathrm{CO}_{2}$ emission allowances.

For each market in which they act strategically, agents choose new actions from instances of a reinforcement learning algorithm, and formulate according bids which they submit to the market operator. In the current version of the model, only generator agents act strategically on the day-ahead electricity market and on the balancing power market.

\section{B. The Day-Ahead Market}

The day-ahead market (DAM) is modeled as a sequence of 24 simple call markets for every delivery hour of the following day. Each agent $i$ owns a set of $G_{i}$ generating units $(g)$. For each unit, the available capacity that an agent can govern in the day-ahead market depends on the trading results on the balancing power market (BPM), as the latter is cleared earlier. If an agent has sold (part of) a plant's capacity on the balancing power market, his available capacity $q^{\text {avail }}$ is given by the total net installed capacity $q^{\text {net }}$ reduced by the amount of committed capacity $q^{\text {comm }}$. The available capacity is calculated separately for every hour $h$; the corresponding committed quantity is the capacity sold in the bidding block $k$ that contains the specific hour, $k(h)$ :

$$
q_{h, i, g}^{D A M, \text { avail }}=q_{i, g}^{\text {net }}-q_{k(h), i, g}^{B P M, \text { comm }}
$$

On every trading day, an agent can submit a set of hourly bids for each power plant it owns. One supply bid consists of a bid quantity and the price at which the quantity is offered. The agent formulates the bids according to the output of the reinforcement learning algorithm, thereby finding the best actions over a two-dimensional action domain. The price dimensions allows bid prices from 0 to $100 \mathrm{EUR} / \mathrm{MWh}$, in 21 discrete steps; the bid quantity that agents can choose ranges from fractions of $\beta=0$ to $100 \%$ of the available capacity, in six discrete steps. The set of bids $b_{h, i, g}^{D A M}$ submitted to the dayahead market by agent $i$ for delivery hour $h$, which contains separate bids for each generating unit $g$, is defined as follows:

$$
B_{h, i}^{D A M}=\left\{\left\langle p_{h, i, g}^{D A M}, q_{h, i, g}^{D A M}\right\rangle: g=1, \ldots, G_{i}\right\}
$$

with

$$
q_{h, i, g}^{D A M}=\beta_{h, i, g} \cdot q_{h, i, g}^{D A M, \text { avail }}, 0 \leq q_{h, i, g}^{D A M} \leq q_{h, i, g}^{D A M, \text { avail }}
$$

If $\beta_{h}$ is equal to zero, no bid is formulated, as bid volumes have to be higher than zero. This situation can be interpreted as total capacity withholding for the respective plant.

Market clearing is effected by sorting all supply bids in ascending, and demand bids in descending price order. In case of equal bid prices, bids are sorted in descending volume order; priority between two identical bids is determined randomly. ${ }^{1}$ The intersection of the so-formed supply and demand curves sets the resulting price $P_{h}^{D A M}$ at which all successful bids are remunerated.

In the simulations presented here, the demand side of the day-ahead market is represented as a fixed price-insensitive load. Data of the hourly system's total load is used for representing electricity demand. The assumption of a fixed load is a useful simplification. In the short-term, it is realistic to assume that electricity consumers do not react to price changes, because they usually do not have any price information at short notice that allows them to adapt their consumption to the price signals. As the focus here is placed on on short-term market dynamics, fixed price-insensitive load is a valid assumption. As it was the case in the real-world system during the time frame under study, overall electric load $L$ never exceeds the total installed net capacity of all generators, i.e.

$$
L_{h} \leq \sum_{i} \sum_{G_{i}} q_{h, i, g}^{n e t} \forall h
$$

\section{The Balancing Power Market}

The implemented balancing power market represents procurement auctions for positive minute reserve, and is designed in a similar fashion as the minute reserve auctions operated by the four German transmission system operators. More precisely, the specifications defined in a recent adjudication issued by the responsible regulatory authority [10] are already represented in the BPM implemented in the electricity market simulation model.

A bid on the balancing power market contains an offer quantity in MW and of two bid prices: the capacity price, i.e. the price for holding capacity in reserve during the whole

\footnotetext{
${ }^{1}$ Before the clearing process, all bids are randomized in order to avoid
} unintended recurrent priorities in cases of identical bids. 
bidding period, and the energy price; i.e. the price a generator is paid for produced minute reserve in case his plant is actually deployed for regulating purposes.

Similarly to the day-ahead market, the domain of possible actions on the market for balancing power market is twodimensional; the two dimensions are capacity prices and energy prices. Possible prices range from 0 to 200 EUR/MW in 21 discrete steps for the capacity ( cap) price and from 0 to 100 EUR/MWh in five steps for the energy price.

Agents with power plants that are technically able to deliver minute reserve (MR) can sell capacity on this market. These plants have to allow fast changes in load and must be ready to be fully activated within 15 minutes. The capability of minute reserve delivery is expressed through the indicator function $I(g, \mathrm{MR})$ which is equal to zero if plant $g$ is slowly controllable (not suitable for minute reserve delivery) and one if it is fast controllable and can, thus, bid on the BPM.

As the balancing power market is cleared before the dayahead market, the agent's available capacity of every power plant that is technically suitable for minute reserve delivery is its net installed capacity, $q_{k, i, g}^{B P M, a v a i l}=q_{i, g}^{\text {net }}$. After deciding which action to take, the agent formulates the bid that he wants to submit to the balancing market operator; the specification of a balancing power bid is given in Formula 5.

$$
\begin{array}{r}
B_{k, i}^{B P M}=\left\{\left\langle p_{k, i, g}^{B P M, \text { cap }}, p_{k, i, g}^{B P M, \text { energy }}, q_{k, i, g}^{B P M}\right\rangle\right. \\
\left.\quad: g=1, \ldots, G_{i} \mid I(g, \mathrm{MR})=1\right\} \\
\text { with } \quad q_{k, i, g}^{B P M}=q_{k, i, g}^{B P M, \text { avail }}
\end{array}
$$

The demand side of the balancing power market is represented as a predefined quantity of positive minute reserve that has to be procured. Six equally long bidding blocks of four hours length are differentiated for every trading day: from 0 to $4 \mathrm{am}$, from 4 to $8 \mathrm{am}$, and so forth. The tendered balancing capacity quantity $Q_{k}^{B P M}$ is equal for every bidding block (for the simulations presented in this chapter, $Q_{k}^{B P M}=$ $3,500 \mathrm{MW} \forall k$ ).

In procurement auctions with two-part bids, the market clearing procedure distinguishes two aspects: the scoring rule and the settlement rule [11]. The scoring rule defines how to compare bids and the settlement rule determines payments. In the balancing market developed here, bids are compared solely on the basis of capacity bid prices, i.e. the bids with the lowest capacity bid price are considered first for holding capacity in reserve, until demand is met. If minute reserve is actually needed for frequency control on the day of delivery, deployment is decided among those bids that had been successful on the trading day. A merit order is constructed based on the energy price only, and bids with lowest energy prices are deployed first, until demand is met. Payments both for holding capacity in reserve and for delivering energy for regulating purposes are based on the respective bid prices. These scoring and settlement rules both correspond to the specifications set by German regulation [10].

\section{Emissions Trading}

The $\mathrm{CO}_{2}$ emission allowance market $(\mathrm{CO} 2 \mathrm{M})$ is executed at the end of each trading day. It is assumed that all agents seek to even up their open positions every day. This entails that agents who sell electricity also make sure to have enough allowances for the carbon dioxide emissions associated to their generation output. Agents who have surplus allowances try to sell them at the market price. Market participants in real-world carbon exchanges also have the possibility of buying (selling) more allowances than currently needed if they expect prices to rise (fall) in the future. Strategies of this kind, i.e. buying and selling allowances to profit from price changes instead of using them directly for compliance can be categorized as speculation. Speculation is not considered in this model.

All generator agents that own fossil fuel fired power plants are initially endowed with a certain amount of $\mathrm{CO}_{2}$ allowances. The initial allocation of allowances is calculated according to a grandfathering rule, i.e. based on past emissions for each single power plant (this approach corresponds to the actual emissions trading procedure fixed in [12] and [13]). The sectors outside the electricity industry that are covered by the emissions trading scheme submit fixed supply and demand quantities every day. As little is known about $\mathrm{CO}_{2}$ mitigation costs of these sectors - and consequently about their valuation for allowances - their parameter values for supply or demand quantities and valuations are calibrated so as to produce average prices that roughly correspond to observed prices in the real-world carbon exchanges.

The agents' daily trading quantities are calculated on the

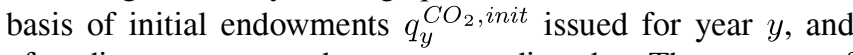
of trading success on the current trading day. The amount of carbon dioxide emitted during electricity generation, $q^{e m i t}$, is determined by volumes sold at the day-ahead electricity market $q^{D A M, \text { sold }}$ and by deployed minute reserve $q^{B P M, d e p l}$. The quantities are multiplied with the emission factor $\omega_{g}$ of plant $g$, quantifying the $\mathrm{CO}_{2}$ emissions associated with every MWh of power output.

$$
q_{t, i}^{C O_{2}, \text { emit }}=\sum_{G_{i}}\left(\sum_{h=1}^{24} \omega_{g} \cdot q_{h, i, g}^{D A M, \text { sold }}+\sum_{k=1}^{6} \omega_{g} \cdot q_{k, i, g}^{B P M, \text { depl }}\right)
$$

The remaining allowance budget that an agent has at his disposal at time $t$ (day of the year $y$ ) is divided by the remaining days for which the allowances were issued in order to calculate a daily budget. This budget is subtracted from the allowance quantity needed for power generation, thus resulting in the bid quantity that agent $i$ submits to the $\mathrm{CO}_{2}$ market operator. In consequence, if an agent's budget for the current day is larger than the need for allowances, his bid quantity becomes negative, which corresponds to a selling bid.

$$
q_{t, i}^{C O 2 M}=q_{t, i}^{C O_{2}, e m i t}-\frac{q_{t, i}^{C O_{2}, b u d}}{365-t-1}
$$

${ }^{2}$ If the deployment of minute reserve becomes necessary, this would occur one day after trading on the balancing power market. For simplicity, it is assumed that minute reserve quantities actually deployed are already known on the trading day. In real-world practice, only around $2 \%$ of procured capacity is actually deployed [10], so these quantities are negligible. 
Bids on the $\mathrm{CO}_{2}$ allowance market contain a volume of allowances $^{3}$ that is offered or asked, a bid price and the compliance period $(c p)$ for which the allowance should be valid (as no speculation is considered, the compliance period is always equal to the current period). Buying bids have positive volumes, and selling offers have negative volumes. Each agent submits one single bid on the allowance market at time $t$ (day of the year $y$ ), representing his daily allowance requirement or surplus which is calculated for the whole portfolio of power plants he owns.

$$
b_{t, i}^{C O 2 M}=\left\langle p_{t, i}^{C O 2 M}, q_{t, i}^{C O 2 M}, c p\right\rangle
$$

The $\mathrm{CO}_{2}$ emission allowance market is modeled as a sealed bid double auction. Demand and supply bids are summed up to form supply and demand functions in the same way as on the day-ahead electricity market, and the uniform market clearing price is determined by the intersection of both curves. At this allocation, a maximum of social welfare is reached.

The remaining allowance budget is updated at the end of each trading day for the following day. The amount of allowances used for emitted $\mathrm{CO}_{2}$ quantities $q^{\mathrm{CO}_{2} \text {,emit }}$ are subtracted from the current budget, and resulting trading volumes $q^{C O 2 M}$,res (positive for bought allowances, negative for sold volumes) are added to it. The budget at time $t=0$ is the initial allowance quantity issued for year $y$.

$$
\begin{gathered}
q_{t+1, i}^{\mathrm{CO}_{2}, \text { bud }}=q_{t, i}^{\mathrm{CO}_{2}, \text { bud }}-q_{t, i}^{\mathrm{CO}_{2}, \text { emit }}+q_{t, i}^{\mathrm{CO} 2 \mathrm{M}, \text { res }} \\
\text { with } q_{0, i}^{\mathrm{CO}_{2}, \text { bud }}=\sum_{G_{i}} q_{y, g}^{C O_{2}, \text { init }}
\end{gathered}
$$

Agents do not act strategically on the market for $\mathrm{CO}_{2}$ emission allowances - they do not set bidding strategies through reinforcement learning. However, the costs incurred from allowance prices influence trading strategies on the electricity markets, as specified in the following section.

\section{E. Market Interrelations}

The three markets that form the electricity sector simulation model are interrelated through the agents' bidding strategies. A power generator has the choice to bid his generating capacity on the day-ahead or on the balancing market (for those plants that fulfill the technical requirements to deliver minute reserve), and has to trade off between these two options. After market clearing on the first market, an agent can bid his remaining unsold capacity on the second market. Through varying the bid quantity on the day-ahead market, agents can influence and optimize their joint strategy on both electricity markets

While optimizing their supply bids, agents consider opportunity costs that they could have achieved on the other market if they had sold their capacity there. Prices for carbon dioxide emission allowances are also included into the reinforcement as opportunity costs. A generator would always have the opportunity to solely sell certificates, thereby realizing a profit.

\footnotetext{
${ }^{3} 1$ EUA (European Allowance) allows for the emission of $1 \mathrm{t}$ of $\mathrm{CO}_{2}$.
}

Consequently, he aims at attaining a profit at least as high as he could have achieved through selling allowances.

Agents learn strategies separately for the day-ahead and for the balancing power market. In the implementation, they have individual instances of the learning algorithm for each of the two markets. Moreover, strategies for each bidding block on the balancing power market and for each hour on the day-ahead market are learned separately. Opportunity costs between the two electricity markets only occur for power plant types that are suitable for delivering minute reserve power. Power output from all other plants can consequently only be bid on the day-ahead market, and opportunity costs from the balancing power market are not considered for these plants.

The behavioral representation of the agents' search for profit maximizing strategies is modeled with Q-learning [14]. For this learning algorithm, different states have to be defined. In the model presented here, states are based on bid prices and trading success. Bid prices can be categorized as low (lower than or equal to one third of the maximum admissible bid price), high (higher than or equal to two thirds of the maximum admissible price) or intermediate (all remaining prices). A bid can further be categorized as marginal or intra-marginal, in which case it was successful, or as extra-marginal for a bid that was not successful. All combinations of bid prices and success form the six states that are differentiated in the model.

Reinforcements $R$ that are fed back to the update function of the learning algorithm are calculated for both power markets after all markets have cleared on the current trading day. They are based on the profit $\pi$ earned on the respective market. In order to facilitate setting initial Q-values for the learning algorithms, reinforcements are set relative to the maximum possible profit $\pi^{\max }$ that an agent can earn on the market. Consequently, the range of possible reinforcements is the same for all learning tasks: $0 \leq R \leq 1$; initial Q-values are set to $Q_{0}=1$. Maximum profits depend on variable costs $c^{v a r}$ of the power plant deployed, and differ across plants.

Most generator agents own a portfolio of power plants over which they can maximize profits. At the same time, bids are set and learned separately for each power plant. Consequently, the reinforcement for learning the bidding strategy of one plant should contain some information about the performance of the whole portfolio. The influence of the portfolio profit on the reinforcement is set through the portfolio integration parameter $\psi$. Throughout the simulations presented here, it is set to $\psi=0.5$. This means that half of the reinforcement is defined through the payoff earned from the power plant for which the strategy is learned, and half of it is given by the performance of the agent's whole portfolio.

$$
\begin{aligned}
R_{h, i, g}^{D A M} & =(1-\psi) \cdot \pi_{h, i, g}^{D A M} / \pi_{i, g}^{D A M, \max } \\
& +\psi \cdot \frac{\sum_{G_{i}} \pi_{h, i, g}^{D A M} / \pi_{i, g}^{D A M, \max }}{G_{i}}
\end{aligned}
$$

with

$\pi_{h, i, g}^{D A M}=q_{h, i, g}^{D A M, \text { sold }} \cdot P_{h}^{D A M}-c^{v a r}-c_{h, i, g}^{B P M, o p p}-c_{h, i, g}^{C O 2 M, o p p}$ 


$$
\begin{gathered}
\pi_{i, g}^{D A M, \max }=q_{i, g}^{\text {net }} \cdot P^{D A M, \text { max }}-c^{v a r} \\
c_{h, i, g}^{B P M, o p p}=I(g, \mathrm{MR}) \cdot P_{k(h)}^{B P M, c a p} \cdot q_{h, i, g}^{D A M} \\
c_{h, i, g}^{C O 2 M, o p p}=P_{t(h)}^{C O 2 M} \cdot q_{h, i, g}^{C O_{2}, \text { emit }}
\end{gathered}
$$

The reinforcement for trading on the balancing power market is defined in a similar manner as on the day-ahead market. If no minute reserve energy is actually deployed for frequency regulation, profits are only defined by capacity prices and noload costs (nolc) over the number of hours per bidding block $|h \in k|$, i.e. the cost for keeping the power plant in a stand-by state. If minute reserve is deployed, no-load costs do not occur and the profit gained from the energy price minus the variable cost has to be added. For simplicity, only the first of the two cases is formulated below. For the calculation of $\pi^{B P M, \max }$, only capacity prices are considered.

$$
\begin{array}{r}
R_{k, i, g}^{B P M}=(1-\psi) \cdot \pi_{k, i, g}^{B P M} / \pi_{i, g}^{B P M, \max } \\
+\psi \cdot \frac{\sum_{G_{i}} I(g, \mathrm{MR}) \cdot \pi_{k, i, g}^{B P M} / \pi_{i, g}^{B P M, \max }}{\sum_{G_{i}} I(g, \mathrm{MR})}
\end{array}
$$

with

$$
\begin{gathered}
\pi_{k, i, g}^{B P M}=q_{k, i, g}^{B P M, \text { cap sold }} \cdot P_{k}^{B P M, \text { cap }}-c^{\text {nolc }} \cdot|h \in k|-c_{k, i, g}^{D A M, \text { opp }} \\
\pi_{i, g}^{B P M, m a x}=q_{i, g}^{\text {net }} \cdot P^{B P M, c a p, m a x}-c^{\text {nolc }} \cdot|h \in k| \\
c_{k, i, g}^{D A M, o p p}=q_{k, i, g}^{B P M, c a p} \cdot \sum_{h \in k} P_{h}^{D A M}
\end{gathered}
$$

\section{VALIDATION}

Empirical validation of agent-based simulation models must take place on two levels: a micro-validation requires a detailed analysis of which behavioral representation is best suited for modeling agents engaged in daily repeated electricity trading. In this context, numerous tests of different learning algorithms (Q-learning, the learning model formulated by Erev and Roth [15], and Experience-Weighted Attraction) have been carried out by the authors. This procedure will not be reported here.

On the basis of a properly micro-validated learning model, the next validation step can be proceeded. The macrovalidation entails the analysis of macro variables that result from the agents' interaction. Here, market prices that come out of simulations with the presented model, run with data input that realistically represents the German electricity sector, are compared to empirically observed prices in order to verify if real-world day-ahead and balancing power market results can be properly reproduced with the simulation model.

In the following, the model is run with data input that characterizes the German electricity industry during the analysis period of 2006. The industry's power plant portfolio is represented in an aggregate way, based on published data about installed capacity. The four dominant players in the German power market (E.ON AG, RWE Power AG, Vattenfall Europe AG and EnBW Kraftwerke AG) are represented in more detail, and further players are introduced so that the overall installed capacity and the proportions of different generation technologies (coal-fired, gas-fired, hydro etc.) are properly represented. Within the power plant portfolio of one generator, all plants using the same fuel or technology are subsumed under one generating unit, and average efficiencies are assumed for these units. The resulting merit order of all power plants is depicted in Figure 5.

The system's total load data provided by the Union for the Co-Ordination of Transmission of Electricity (UCTE) constitutes the data input for the demand side. Those days for which the system's total load is published (i.e. every third Wednesday of a month) are simulated, and resulting prices are compared to empirically observed prices at the European Energy Exchange (EEX) spot market and at the German balancing power markets in the year 2006. As the realworld markets may show extraordinary prices on the specific simulated days, additional average daily courses of prices over all workdays of the same month are calculated and compared to the simulation outcomes.

In all simulations, agents apply Q-learning with a learning rate of $\alpha=0.5$, a discount rate of $\gamma=0.9$ and an $\varepsilon$-greedy action selection rule with $\varepsilon=0.2$. Simulations are run over 7,300 iterations, and results are averaged over ten simulation runs with different random number seeds. The outcome of one simulation run is defined as the average market price over the last 365 iterations.

Figures 1 and 2 show examples for simulation results. Continuous lines plot the simulation outcome for the simulated day of the month; dashed lines plot the empirically observed prices of the same day, and dotted lines represent average prices over all workdays of the specific month. Top figures display hourly results on the day-ahead market, where empirically observed prices correspond to prices for hourly contracts at the EEX spot market. Bottom figures show results from the balancing power market for the six bidding blocks, and empirically observed prices are averaged over the prices published by the four balancing market operators. ${ }^{4}$

Prices in summer and transitional (spring/fall) months (see example in Figure 1) are quite closely reproduced by the simulation model. Prices in winter months (see example in Figure 2), however, show larger deviation between simulation outcomes and real-world prices. In some hours, prices even exceed 100 EUR/MWh; as the agents' action domains in the simulations only allow for bid prices up to $100 \mathrm{EUR} / \mathrm{MWh}$, prices above this level cannot be replicated by construction of the model. Enlarging the action domain might be a way to ensure that prices higher than $100 \mathrm{EUR} / \mathrm{MWh}$ can also be simulated. However, a sensitivity analysis reveals that

\footnotetext{
${ }^{4}$ In 2006, bidding blocks were defined differently across the four balancing power markets existing in Germany. For comparison with the simulated data average prices for the six defined bidding blocks are interpolated. Since December 2006, all four transmission system operators implement one joint minute reserve procurement auction with six bidding blocks equal to those in the simulation model.
} 

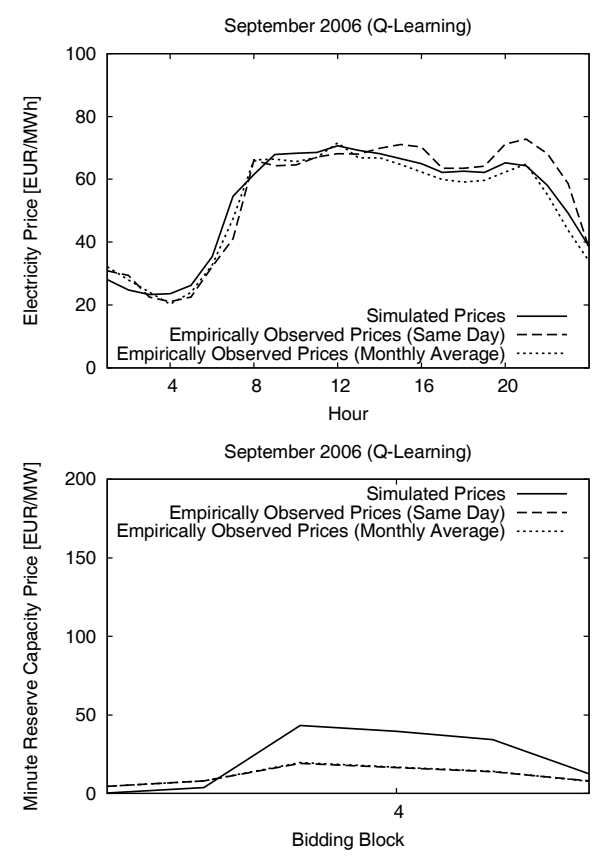

Fig. 1. Example results for September 2006: simulated and real-world prices on the day-ahead (top) and balancing power market (bottom)

simulation outcomes are quite sensitive towards the definition of the agents' action domain. If the range of possible bid prices on the day-ahead market is augmented to 110,120 or $150 \mathrm{EUR} / \mathrm{MWh}$, average yearly prices rise by $6.2,12.5$, and $31.3 \%$, respecitively.

The simulated prices observed on the two electricity markets are a consequence of agents bidding subsequently on these markets and on the $\mathrm{CO}_{2}$ allowance exchange, and optimizing their strategies in face of market interrelations. Demand on the balancing power market, i.e. tendered minute reserve capacity, is equal for all bidding blocks. This market is cleared first, and the day-ahead market is operated subsequently. As the available supply and demand quantities in the balancing power market are the same in every hour, differences in prices between the bidding blocks can only result from the inclusion of opportunity costs into the agents' reasoning.

The simulation outcome on the balancing power market shows characteristic daily courses of prices, in which capacity prices in bidding blocks 3 and $4-$ and 5 in winter months - are considerably higher than those in the nocturnal bidding blocks. Similar characteristics can be observed in the realworld balancing power markets in Germany, although the high prices in the fifth bidding block that occur in most winter months are not reproduced by the simulation model. However, the observation that the basic characteristics and the order of magnitude of prices for day-ahead contracts and for balancing power are well simulated is an encouraging result and strengthens confidence in the model validity.

The effect of $\mathrm{CO}_{2}$ emissions trading on simulated prices is roughly comparable to that observed in the real market; a large share of opportunity costs are successfully passed on to electricity bids, which ultimately raises electricity prices. This
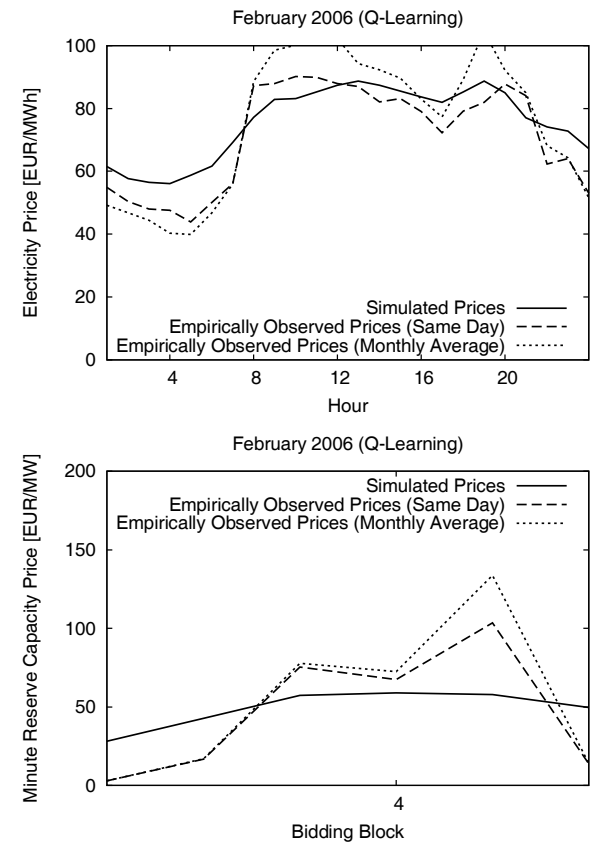

Fig. 2. Example results for February 2006: simulated and real-world prices on the day-ahead (top) and balancing power market (bottom)

can be concluded from a comparison of prices in simulations with and without emissions trading (not reported here).

\section{IMPACT OF TENDERED BALANCING CAPACITY ON ELECTRICITY PRICES}

The agent-based electricity sector simulation model presented in this paper can be used as a means of testing different market structures and market mechanisms in order to evaluate their influence on power trading outcomes, especially on resulting market prices. Among the scenarios that can be simulated with this model, one problem of interest in the German electricity sector is exemplified in the following.

In accordance with many other studies about European electricity markets, an expertise by order of the German Federation of Industrial Energy Consumers comes to the conclusion that electricity markets in continental Europe are not structured in a sufficiently competitive way. As regards the interplay between the day-ahead electricity market and the balancing power market, it furthermore concludes that the latter particularly offers potential for market power exertion through subtracting capacity from wholesale trading [16].

In real-world practice during the year 2006, the procured positive balancing power capacity was nearly 4,000 MW for primary and secondary reserves, and between 3,150 and 3,420 MW for minute reserve. In the model, procured minute reserve capacity is set to 3,500 $\mathrm{MW}$, while primary and secondary reserve procurement is not considered. In order to analyze whether and to what extent the effect assumed in the expertise actually occurs, the amount of tendered minute reserve on the balancing power market is varied from 1,000 MW to 13,000 MW, and simulated prices are compared.

Classical electricity market models that assume no strategic bidding would also suggest that market prices rise when 
demand increases. This is directly explained by the merit order: if load is high, more expensive generating units must be deployed in order to satisfy demand. Thus, only in those cases in which bidders can successfully raise market prices to an extent that cannot be explained by the underlying cost structure alone, it can be concluded that there exists an increased "potential for market power exertion".

On the balancing power market, which is cleared first, 7,000 MW of hydroelectric capacity is available at a no-load costs of 0 EUR/MW per hour and variable (operating) costs of 1.5 EUR/MWh. Additional demand can be satisfied with the available capacity of the next expensive gas-fired power plants (no-load costs $100 \mathrm{EUR} / \mathrm{MW} * \mathrm{~h}$, variable costs $45 \mathrm{EUR} / \mathrm{MWh}$ ) in all simulated scenarios of tendered balancing capacity. Expensive oil-fired power plants do not need to be deployed for minute reserve purposes, unless they underbid lower cost hydroelectric or gas-fired generating capacity.

The merit order shift on the day-ahead market, which is cleared secondly, partly depends on trading results on the balancing power market. If least-cost plants are deployed for minute reserve, the variable generating cost of the last unit necessary to satisfy demand is 4.5 EUR/MWh in a few hours of very low demand, 20-22 EUR/MWh in the largest part of all hours, and 45 EUR/MWh in hours of very high demand and high tendered minute reserve.

The simulation outcomes confirm the effect assumed in the expertise. Figure 3 (top) shows simulated prices on the day-ahead market as a function of tendered minute reserve quantities. Over the simulated range, a nearly linear relation between balancing power quantities and resulting prices can be observed. The slope of the curve is steeper for cases with higher demand - such as in winter months - than in times of low demand (Figure 3 displays the two months with the highest and lowest slope for each market). The effect of varying tendered minute reserve capacity is stronger on the balancing power market. As depicted in Figure 3 (bottom), higher tendered capacities lead to considerably higher minute reserve prices. The functional relation is weakly concave. Yearly average prices increase from less than 15 up to more than $90 \mathrm{EUR} / \mathrm{MWh}$, which corresponds to a sextupling of prices from 1,000 to $13,000 \mathrm{MW}$ of tendered reserve capacity.

The fact that prices do not only decrease when tendered minute reserve quantities rise above the level of 7,000 MW suggests that the dynamics of competition on the balancing power market are more influenced by the supply/demand ratio or opportunity costs from the day-ahead market than by the underlying cost structure. This can be seen as an indicator for an increasing market power potential when tendered minute reserve quantities are elevated. Higher demand on the balancing power market reduces supply-side competition, so agents are less forced to bid competitively, leading to higher market prices. Besides, if more capacity is committed on the balancing power market, less capacity is available on the day-ahead market, leading to the same effects on this market, too. As opportunity costs are taken into account, high prices on one market tend to result in higher prices on the other market. This effect especially occurs on the balancing power market, as it is stronger influenced by the day-ahead market than vice versa.
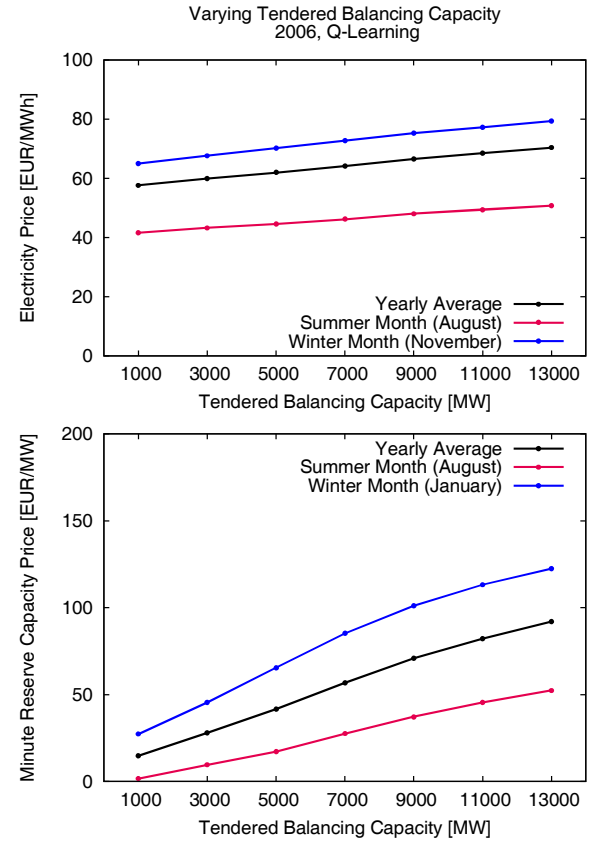

Fig. 3. Yearly average prices on the day-ahead (top) and balancing power market (bottom) for different tendered minute reserve quantities

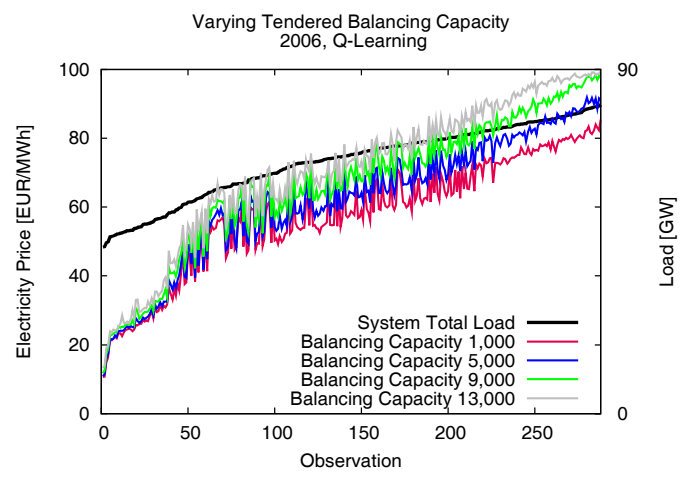

Fig. 4. Day-ahead market prices for different tendered minute reserve quantities, sorted by total demand

Figure 4 shows the prices resulting on the day-ahead market for all observations (i.e. for all $12 * 24$ simulated hours), and for varying tendered minute reserve quantities. Observations are sorted by demand quantities in the corresponding hours. What can be observed here is that price increases resulting from elevated tendered balancing power quantities are stronger in high demand hours and have a negligible effect in hours of very low demand. For very high demand and high tendered balancing capacity, prices even climb up close to the maximum possible price of $100 \mathrm{EUR} / \mathrm{MWh}$.

\section{CONCLUSION}

In this contribution, an agent-based simulation model representing the core features of the German electricity industry is presented. The model comprises a day-ahead market for hourly electricity delivery contracts, a procurement market for positive minute reserve and a market for $\mathrm{CO}_{2}$ emission 
allowances. Simulated prices from this model are close to real-world prices in many months of the year 2006, both on the day-ahead market (compared to EEX prices) and on the balancing power market (compared to prices on the balancing power markets operated in Germany). Besides, the influence of $\mathrm{CO}_{2}$ emissions trading on electricity prices is comparable to observations from real-world markets.

The presented model can be used to analyze a variety of possible market structures and market mechanisms with the aim of finding good market designs that take into account market interrelations and other aspects of real-world power systems. Analyses of this kind have been conducted by the authors, and additional scenarios are currently developed. Results from these simulations demonstrate the usefulness of the agent-based simulation model presented here. One example presented in this paper is the influence of tendered balancing capacity on prices on both simulated electricity markets. Considerable rises in prices can be observed for increasing minute reserve procurement quantities; in high demand hours, this leads to a considerable potential for agents to drive market prices up. The model presented here should be further applied to test alternative market designs in order to find the best options of preventing generators from exerting market power.

\section{APPENDIX}

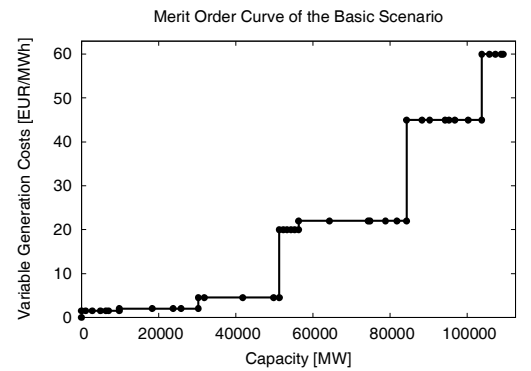

Fig. 5. Merit order of installed generating capacity

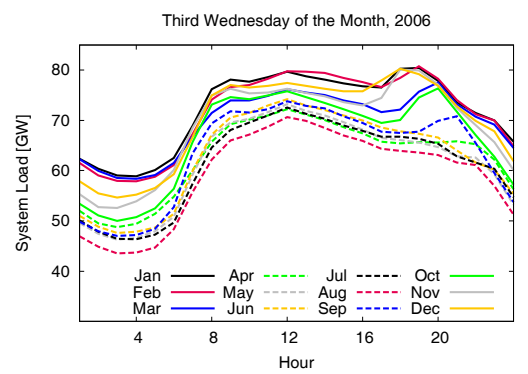

Fig. 6. UCTE load for 2006

\section{REFERENCES}

[1] A. E. Roth, "The Economist as Engineer: Game Theory, Experimentation, and Computation as Tools for Design Economics," Econometrica, vol. 70, pp. 1341-1378, 2002.

[2] L. Tesfatsion, Handbook of Computational Economics, Volume 2: AgentBased Computational Economics. North-Holland, 2006, ch. AgentBased Computational Economics: A Constructive Approach to Economic Theory, pp. 831-880.
[3] A. Weidlich and D. Veit, "A Critical Survey of Agent-Based Wholesale Electricity Market Models," Energy Economics, p. in press, 2008.

[4] J. Sun and L. Tesfatsion, "Dynamic Testing of Wholesale Power Market Designs: An Open-Source Agent-Based Framework," Computational Economics, vol. 30, no. 3, pp. 291-327, 2007.

[5] J. Nicolaisen, V. Petrov, and L. Tesfatsion, "Market power and efficiency in a computational electricity market with discriminatory double-auction pricing," IEEE Transactions on Evolutionary Computation, vol. 5, no. 5, pp. 504-523, 2001.

[6] J. Bower and D. Bunn, "Experimental analysis of the efficiency of uniform-price versus discriminatory auctions in the England and Wales electricity market," Journal of Economic Dynamics \& Control, vol. 25, pp. 561-592, 2001

[7] T. D. H. Cau and E. J. Anderson, "A co-evolutionary approach to the tacit collusion of generators in oligopolistic electricity markets: piecewise linear bidding structure case," in Proceedings of Congress on Evolutionary Computation (CEC2003), vol. 4, 2003, pp. 2306-2313.

[8] A. Bagnall and G. Smith, "A Multi-Agent Model of the UK Market in Electricity Generation," IEEE Transactions on Evolutionary Computation, vol. 9(5), pp. 522-536, 2005.

[9] A. Rupérez Micola, A. Banal Estañol, and D. W. Bunn, "Incentives and Coordination in Vertically Related Energy Markets," Discussion Paper SP II 2006 - 02, Wissenschaftszentrum Berlin, 2006.

[10] Bundesnetzagentur, "Adjudication about the procedure of minute reserve procurement in Germany," 29. August 2006, Bonn, 2006.

[11] H.-P. Chao and R. Wilson, "Multi-Dimensional Procurement Auctions for Power Reserves: Robust Incentive-Compatible Scoring and Settlement Rules," Journal of Regulatory Economics, vol. 22, no. 2, pp. 161183, 2002.

[12] European Union, "Directive 2003/87/EC of the European Parliament and of the Council of 13 October 2003 establishing a scheme for greenhouse gas emission allowance trading within the Community," Official Journal of the European Union, L 275/32, 2003.

[13] German Federal Ministry for Environment, Nature Protection and Reactor Safety, "National Allocation Plan for Germany 2005-2007," Berlin, 2004.

[14] C. J. C. H. Watkins, "Learning from Delayed Rewards," Ph.D. dissertation, Cambridge, 1989

[15] I. Erev and A. E. Roth, "Predicting How People Play Games: Reinforcement Learning in Experimental Games with Unique, Mixed-Strategy Equilibria," American Economic Review, vol. 88(4), pp. 848-881, 1998.

[16] C. von Hirschhausen, H. Weigt, and G. Zachmann, "Preisbildung und Marktmacht auf den Elektrizitätsmärkten in Deutschland - Grundlegende Mechanismen und empirische Evidenz,' Expert's report by order of Verband der Industriellen Energie- und Kraftwirtschaft e.V. (VIK) Dresden, 2007.

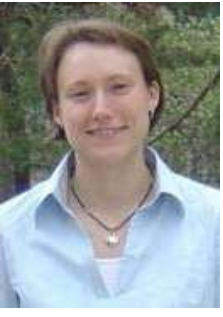

Anke Weidlich is a $\mathrm{PhD}$ student at the University of Mannheim, Business School. She obtained a diploma degree in Industrial Engineering and Business at the University of Applied Sciences in Wedel, and a Diplôme d'Etudes Supérieures Spécialisées degree in Energy Economics and Energy Policy from the University Paris X Nanterre and CEA Saclay.

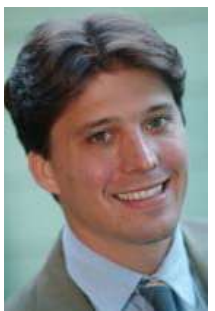

Daniel J. Veit is a full professor and chai in business administration and information systems e-business and e-government at University of Mannheim, Business School. He holds a diploma degree (M.Sc. level) in mathematics and computer science from University of Giessen as well as a doctorate in economics and business engineering and a habilitation degree in business administration from University of Karlsruhe (TH). 